\title{
TRANSMISSIÓ DEL PATRIMONI I MERCAT IMMOBILIARI URBÀ. L'HABITATGE DE LES FAMÍLIES ARTESANES EN LA VILA D'ALZIRA DURANT ELS SEGLES XIV-XV
}

\author{
TRANSMISSION OF THE PROPERTY AND ITS MARKET. \\ ARTISANSHIP'S HOUSEHOLD \\ IN THE VILA OF ALZIRA \\ DURING THE $14^{\text {th }}$ AND $15^{\text {th }}$ CENTURIES
}

\author{
IVAN MARTÍNEZ ARAQUE \\ Universitat de València ${ }^{1}$
}

\begin{abstract}
Resum: L'artesanat fou un col-lectiu destacat en l'àmbit del conjunt de viles que formaven el País Valencià en la baixa Edat Mitjana, també en el cas d'Alzira. En el següent article tractem d'oferir una anàlisi d'aquest heterogeni grup social mitjançant un dels principals espais on desenvolupava la seua activitat, l'obrador o la casa. I això a partir de la localització de bona part de la menestralia en el centre urbà, també de les tasques que portava a terme en l'àmbit domèstic, passant per la transmissió del patrimoni o en quines condicions accedia al mercat immobiliari. En definitiva, pretenem interrogar-nos sobre com s'inseria l'habitatge en les estratègies familiars $i$ quin paper jugava en les lògiques que permetien la reproducció social de l'artesanat.
\end{abstract}

Paraules clau: Viles valencianes; Artesanat; Manufactura; Habitatge; Transmissió de la propietat; Mercat immobiliari urbà; Urbanisme.

\begin{abstract}
The artisanship was a very important group into the bourgs that belonged to the kingdom of Valence in the Later Middle Ages. This was also true in Alzira. The aim of this essay is to analyze this varied social group using one of the main places in which they developed their activity, the workshop or the house. And it all from the location of most of the artisans in the urban center and also from the tasks that they developed in their domestic sphere, including the transmission of the property and the characteristics of the Property Market. In conclusion, we want to ask ourselves about how families included the household in their strategies and what was its role in the rules that allowed the social reproduction of the artisanship.
\end{abstract}

Keywords: Valencian Bourgs; Artisanship; Manufactures; Household; Transmission of Property; Property Market; Urbanism.

\footnotetext{
${ }^{1}$ Investigador de la Universitat de València dins el projecte d'investigació Nivells de vida, pautes de consum i diferenciació social en la baixa Edat Mitjana (ref. HUM005-05144/HIST)
finançat pel Ministeri de Ciència i Innovació.
} 


\section{SUMARI}

I. Una aproximació sociotopogràfica.- II. L'obrador, la casa i els interiors domèstics.- III. Les donacions i les herències, la família i la casa.- IV. El mercat immobiliari en la vila.- V. Habitatges i famílies artesanes.

L'ocupació del territori i la colonització que portà a terme la societat feudal van provocar un tall irreversible en el desenvolupament de la medina d'al-Jazira. Si més no, suposà l'expulsió de bona part de la població andalusina, la seua despossessió, el seu trasllat forçós cap a altres indrets o la segregació en un apartat del raval oriental de l'Alquenència, en la moreria $^{2}$. Certament, el lloc oferia unes condicions aptes per a la ubicació dels nous efectius humans. A la seua condició com a pas del Xúquer en la via tradicional que anava de València a Xàtiva i la ruta que comunicava l'interior de les valls muntanyenques amb la costa, s'unia la presència d'importants infraestructures que podien ser reutilitzades, entre elles, part de les instal-lacions de transformació o el circuit emmurallat ${ }^{3}$. En el seu interior, les mesquites foren convertides en noves esglésies; allò que fou centre de la urbs, amb el soc i les botigues, va ser interpretat, segons el model de les ciutats medievals occidentals, com la plaça major i seu del mercat setmanal. Ensems a la creació de les noves institucions municipals esteses al conjunt de viles o llocs, el bell mig de la nova vila esdevingué el seu centre polític, amb la cort del batlle local, la sala del consell o la presó $^{4}$.

Malgrat aquesta aparent continuïtat física del poblament i d'alguns dels seus elements, però, no devem obviar el canvi profund en les relacions

${ }^{2}$ En diverses alqueries de la Ribera que van ser habitades pels colons, com ara Polinyà Fortaleny, Nacla o Riola, es donaren com a parcel-les de terra diverses mesquites ensorrades els seus fossars, Arxiu de la Catedral de València, pergamins 1524, 1526, 1527 o 1529. La primera réferència que tenim respecte la moreria d'Alzira data ja del' 1248, després de l'ordre d'expulsió general dels musulmans, Ma Desamparados CABANES, Ramon FERRER, Llibre del Repartiment, II, Saragossa, 1979, doc. 928. Tot i això, Josep Torró situa la seua fundació en un moment més tardâ, el 1274, J. TORRÓ, El urbanismo mudéjar como forma de resistencia. Alquerías y morerías en el reino de Valencia (siglos XIII-XVI), "VI Simposio Internacional de Mudejarismo", Terol, 1996, pp. 535-598. Pel que fa a l'evolució demogràfica de la població indígena, Antoni FURIÓ, El camperolat yalencià en l'Edat Mitjana. Demografía i economia rural en la Ribera. (segles XIII-XVI), Tesi doctoral inèdita, Valencia, Universitat de València, 1986 , pp. 73-94, i sobre l'aljama musulmana en el segle XV. Manuel RUZAFA, Un conflicto económico y mental entre dos áreas marginadas. El fracaso del proyecto de ampliación de la morería de Alzira sobre el burdel (1457-1459), "Al-gezira", 4-5 (1988), pp. 75-88.

${ }^{3} \mathrm{El}$ primer anell de defensa, d'herència andalusina, pràcticament no precisà de grans obres fins ben entrat el segle XVI. Áixò no obstant, s' hagueren de construir altres barreres que serviren per aturar les riuades del Xúquer, Agustí FERRER ClARI, Les muralles d'Alzira, escut de la ciutat $i$ clau del Xúquer dins Castells, torres i fortificacions en la Ribera del Xúquer (A. FURIÓ, J. APARICI, eds.), València, 2002, pp. 75-87.

${ }^{4} \mathrm{~A}$. BAZZANA, L'évolution du cadre urbain a l'époque médiévale: quelques exemples en Pays Valencien, dins "Plazas" et sociabilité en Europe et Amérique Latine, Madrid, 1982, pp. 19-37. 
socials que la dotava de nous significats. ${ }^{5}$ La trama urbana, llevat de les vies principals, es veié completament alterada al cap d'uns anys, ja que la de l'època andalusina responia a unes necessitats que en absolut responien a les dels nous pobladors, començant per l'organització del territori en el conjunt de la comarca i passant per la configuració dels mateixos habitatges ${ }^{6}$. En el cas andalusí, el pati central de la casa servia d'aglutinador per a l'eixamplament del grup domèstic en diferents unitats constructives al seu voltant a mesura que la família extensa anava augmentant; l'agrupament d'aquests conglomerats en illes no seguia, doncs, una planificació pautada pels poders públics ${ }^{7}$. Justament, la legislació i la religió islàmiques sancionaven la preeminència de l'esfera privada pel que fa a aquestes qüestions.

\section{UNA APROXIMACIÓ SOCIOTOPOGRÀFICA}

Hi ha un aspecte que colpeix pel que fa a les cases dels colons cristians en els centres urbans valencians i és la seua relativa homogeneïtat de nord a sud del país. Les illes estaven formades per dues rengleres de cases comunament, $\mathrm{i}$ aquestes es juxtaposaven a partir de les parets mitjanceres, que servien com a front d'agregació. En zones on el relleu era més difícil o hi havia altres elements que les distorsionaven, les condicions es podien veure alterades, com ara en passar a ser una sola fila d'immobles als voltants de la muralla, que havia de respectar, teòricament, el corredor de ronda. Per una altra banda, els habitatges estaven constituïts per tres o quatre crugies perpendiculars al carrer, cap a on tenien la seua principal via de

\footnotetext{
${ }^{5}$ Sense anar més lluny, tot i mantenir el nom, la vila de Cullera no s'eregí sobre la mateixa medina de Qulayra, Fernando COTINO, Miquel ROSSELLÓ, Nuevos datos sobre el urbanismo islámico y bajomedieval de Cullera, "Qulayra. Revista d'Årqueologia i Estudis Històrics", 1 (2005), pp. 55-85.

${ }^{6}$ De fet, la Ribera comptava amb més dos centenars d'alqueries abans de la conquesta, formades per grups reduïts de famílies musulmanes que compartien els conreus dins un sistema hidràulic; després, aquestes passaren a ser la meitat, Josepa CORTÉS ET AL:, Les alqueries de la Ribera, assaig d'identificació i localització dins Economia agrària i història local (I Assemblea d'Història de la Ribera), València, 1981, pp. 209-264.

${ }^{7} \mathrm{El}$ cas que millor coneixem sobre l'evolució urbanística musulmana és el de la regió de Múrcia, un balanç interessant en Pedro JIMÉNEZ, Julio NAVARRO, El urbanismo islámico y su transformación después de la conquista cristiana: el caso de Murcia, dins La ciudad medieval. de la casa al tejido urbano. Actas del primer Curso de Historia y Urbanismo Medieval organizado por la Universidad de Castilla-La Mancha (J. PASSINI, ed.), Conca, 2001, pp. 71-129. Al País Valencià, en relació al període andalusí, l'estuḍi arqueológic de la casa musulmana ha estat un element de primer ordre per entendre les relacions socials lligades als andalusins, Andrée BAZZANA, Maisons d'al-Andalus. Habitat médiéval et structures du peuplement dans l'Espagne Orientale, Madrid, 1992, o Josep IVARS, J. TORRÓ, La vivienda rural mudéjar y morisca en el sur del País Valenciano, dins La maison hispano-musulmane. Apports de l'archeologie (A. BAZZANA, J. BERMÚDEZ, eds.), Granada, 1990, pp. 73-98. Treballs que contradiuen la hipòtesi d'Abel Soler, que fa prevaldre el poder estatal en el desenvolupament urbanístic de la medina d'al-Jazira, A. SoLER, Alzira de Xúquer: gènesi urbana $i$ urbanisme planificat a la cora andalusina de València (segle IX), dins Castells, torres i fortificacions, ob. cit., pp. 51-74.
} 
ventilació, i que formaven les diferents estances al seu si ${ }^{8}$. Així doncs, les seues mesures s'adaptaren a la unitat bàsica de reproducció de la societat feudal, que era la família nuclear. Les dades de què es disposa en l'àmbit valencià parlen de cases quadrades o rectangulars d'unes mides entre $45 \mathrm{i}$ $70 \mathrm{~m}^{2}$ de forma usual, si bé n'hi havia de més de 90 , especialment on existia més sòl disponible, com en els ravals ${ }^{9}$.

I és que el nou sistema social que es va anar implantant tenia com a base unes heretats fragmentades pel terme i unes explotacions endegades per cadascuna de les famílies conjugals, que, alhora, exigien un cert agrupament poblacional. Es tractava d'un factor que permetia un major control sobre els habitants, judicial o fiscal, i, sobretot, una exacció més adient de la renda. No debades, les delimitacions i assignacions dels hàbitats correspongueren als poders feudals, en primer terme a la monarquia ${ }^{10}$.

Això no obstant, en una anàlisi més profunda, també en els documents, es manifesta que el pretés urbanisme ordenat cristià no ho era tant. Malgrat l'articulació del nou règim municipal o el desenvolupament de les competències de control urbanístic de la mà del mostassaf, fa la impressió que la vila d'Alzira va créixer de forma un tant desballestada durant els primers decennis: el 1271 Jaume I hagué de reconéixer als propietaris de cases els embans amb mides excessives que s'enlairaven sobre els carrers, els quals dificultaven el pas de carros o de les comitives, i es palesava que

${ }^{8} \mathrm{La}$ bibliografia respecte al tema és vastíssima en l'àmbit occidental europeu, cal assenyalar alguns treballs clàssics com els de Jean CHAPELOT, Robert FOSSIER, Le village et la maison au Moyen Age, París, 1980, o l'especial de la revista "Archeologia medievale", 7 (1980), que suposaren un autèntic esforç multidisciplinar al voltant de l'habitătge durant els' segles medievals. Sobre la cultura material, que té un dels seus espais principals l'àmbit domèstic, Ricardo IZQUIERDO BENITO, La cultura material en la Edad Media. Perspectivas desde la arqueología, Granada, 2008. Al voltant de les perspectives respecte els nivells de vida, Chrstopher DYER, An Age of Transition? Economy and Society in England in the Later Middle Ages, Oxford, 2001. Quant als estudis en les petites comunitats valencianes: Salvador VERCHER LLETí, Casa, família i comunitat veïnal a l'Horta de Valéncia. Catarroja durant el regnat de Ferran el Catolic (1479-1516), Catarroja, 1992; J. TORRÓ, La formació d'un espai feudal. Alcoi de 1245 a 1305, València, 1992: Carmel FERRAGUD DOMINGO, El naixement d'una vila rural valenciana. Cocentaina, 1245-1304, València, 2003; també el treball de Ferran GARCIAOLIVER, Pautes de consum i nivells de vida de la pagesia catalana: la casa $i$ l'interior domèstic, dins Condicions de vida al món rural. Cinque Congrés sobre sistemes agraris, organització social i poder local (J. BOLÒS, A. JARNÉ, E. VICEDO, eds.), Lleida, 2006, pp. 47-66. Per a un repàs bibliogràfic remetem al monogràfic preparat en ocasió de l'XI Assemblea d'Hisțòria de la Ribera que va tractar aquest tema, S. VERCHER, L'habitatge: la casa $i$ l'interior domèstic. Guia bibliogràfica, Corbera, 2005.

${ }^{9}$ Sembla que no fou habitual, en els territoris de reialenc, que les autoritats actuaren com a promotors i la iniciativa constructiva va correspondre a cada particular. En el llibre del repartiment o en els successius lliuraments de la monarquia el que es produí sovint foren donacions de solars en el segle XIII. En la Ribera, per estimular l'atracció d'immigrants mudèjars en el segle XV, el senyors d'Alberic i de Torís manaren construir diverses vivendes, seguint el model cristiă, Inmaculada RoMÁn, Rosa SESER, Pilar AGUILÓ, Formas constructivas en alquerías valencianas a finales del siglo XV. Aportación documental, "Arqueología medieval española. II Congreso", III, Madrid, 1987, pp. 653-660.

${ }^{10}$ Pierre GUICHARD, Al-Andalus frente a la conquista cristiana. Los musulmanes de Valencia (siglos XI-XIII), València, 2001, pp. 238-256. En altres àrees on el procés d'implantació del feudalisme va ser gradual: en el comtat de Barcelona, Maria SolER i SALA, Feudalisme $i$ nucleació poblacional. Processos de concentració de l'hàbitat al comtat de Barcelona entre els segles X $i$ XIII, "Acta historica et archaelogica medievalia", 23-24 (2002-2003) pp . 69-95; $\mathrm{o}$ al nord de Castella, Ignacio MARTín VISO, Riflessioni sull'incastellamento nella Penisola Iberica: la Castiglia dell Ebro e la Transierra di Madrid, "Archeologia Medievale", XXVIII (2001), pp. 83-107. 
no sempre es respectava la línia de façana; el 1321, Jaume II tornà a insistir sobre les mesures que calien ser respectades; fins i tot, una ordenació promulgada pel consell recordava aquesta mateixa circumstància el $1386 .{ }^{11} \mathrm{~A}$ més a més, els conflictes per les delimitacions de les propietats urbanes solien ser tan habituals com en les terres. I és que a voltes s'aprofitava qualsevol "raconet" per edificar-hi' ${ }^{12}$. Això obligava, entre d'altres, a signar davant notari a totes les parts per a què respectaren les servituds de pas, d'aigües, etc.

Malauradament, fins a la segona meitat del segle XIV, tot just quan s'acabaren de configurar els consells locals, no disposem de documentació municipal important, llavors és quan comencen a ser abundants igualment els protocols notarials $i$ on trobem un major nombre de referències pel que fa als habitatges dels artesans. Per a aquestes dates, segons els registres del llibre de la peita, la qual gravava part dels béns immobles dels veïns, la població del seu terme se situava entre les més importants del regne, darrere de Morella i Xàtiva, amb més de 1.800 caps de família anotats envers el 1400 , i en la vila el col·lectiu de menestrals suposava una quarta part de tots els contribuents [vid. Annex II] $]^{13}$.

En relació al tema que ens ocupa, una imatge característica del conjunt de l'artesanat en aquests centres semiurbans eren els petits obradors, generalment ubicats dintre les mateixes cases de la menestralia, encara que no hem d'oblidar que, si bé alguns formaven part d'un procés productiu complex, no es tractava de les úniques infraestructures industrials existents; n'hi hagué d'altres que requerien de grans recursos, com ara les tintoreries, almàsseres o molins. ${ }^{14}$ Aquells tallers, duts endavant pel conjunt de la família artesana $\mathrm{i}$ amb uns capitals fixos sovint modestos, els trobem escampats per la vila, principalment, i els ravals, sobretot el de l'Alquenència, gràcies a la proximitat a les diverses instal lacions que s'hi ubicaven, des de diferents establiments industrials o els hostals, passant pel convent dels agustins o el bordell. Segons el llibre de la peita del 1400-1404, en el clos urbà residien ben bé dos terços dels artesans presents, mentre que en els ravals es concentraven aquelles professions més contaminants o molestes, com les relacionades amb el metall [Annex III] ${ }^{15}$.

\footnotetext{
${ }^{11}$ José Ma PARRa, Los Pergaminos de la Cancillería Real, Alzira, 1987, perg. 5 i 21; Aureliano LAIRÓN PLA (ed.), Libre de diverses statuts e ordenacions fets per lo consell de la vila de Algezira, València, 2001, estatut 115. 1403.

${ }^{12}$ Arxiu Municipal d'Alzira, Protocols, Protocols de Bernat Llorenç, sign. 040/12, 5-VII-

${ }^{13}$ Dels més de 600 caps de família que hem pogut resseguir en el llibre de la peita del 1400-1404 dins els murs, 157 són catalogats com a artesans. AMA, Hisenda, Contribucions, Llibres de la Peita, sign. 230/1-2.

${ }^{14}$ Quant a aquestes últimes infraestructures en la comarca de la Ribera, A. FURIÓ, Luis P. MARTINEZ, Assuts i molins sobre el Xúquer en la baixa Edat Mitjana, "IV Congrés d'Arqueologia Medieval Espanyola", IV, Alacant, 1994, pp. 575-583.

${ }^{15}$ Sobre la peita i els padrons de riquesa d'Alzira, A. FuRIó, El camperolat valencià, pp. 46-73, Tomàs PERIS ALBENTOSA, Anàlisi crítica $i$ guia metodologica dels cappatrons de la peita de l'Arxiu Municipal d'Alzira, Al-Gezira, 1 (1985), pp. 113-147.
} 
D'un altre costat, la documentació notarial permet identificar algunes de les àrees dins el centre urbà cobejades per l'artesanat més reeixit. Una d'aquestes era el carrer Major, en les proximitats de llocs de trafegament de persones i productes de tota la comarca com l'almodí, el mercat setmanal o les parades diàries de venda d'aliments, on es trobaven les botigues dels mercaders més importants i les oficines dels notaris de la vila. També les fonts ens informen d'un barri especialitzat dels fusters, situat en un dels eixos transversals de la vila que donava al portell de la muralla i a la rambla del riu, anomenat la Fusteria. Precisament, és en l'esplanada propera del braç del Xúquer on hi havia el mercat setmanal de ramat i on es dipositaven els troncs que abaixaven pel riu per a què s'eixugaren [Annex I] ${ }^{16}$.

En les viles valencianes, la ubicació de l'artesanat sembla respondre, en primer terme, a diverses motivacions: a factors tècnics i econòmics o a solidaritats, a banda de professionals, veïnals, familiars o clientelars. Ara bé, el que sí que s'observa cada volta com més va és la delimitació per part de les autoritats locals d'espais "d'excel·lència urbana", diem-ne que s'hi desenvolupà una política urbanística que prioritzava "l'embelliment" de les zones on hi havia els principals edificis del poder i les residències de les elits $^{17}$. En la vila d'Alzira, des de finals del segle XIV i al llarg del XV, assistim a l'adquisició i ensorrament d'obradors contigus a la sala del consell per a la seua ampliació, així com a l'inici de les obres d'eixamplament de l'almodí, al mateix temps que s'allunyaven els llocs diaris de venda de fruites i hortalisses o el de la carnisseria, que es va situar prop del barri de la Fusteria, al·legant la seua insalubritat ${ }^{18}$. Mentre, l'oligarquia esdevingué cada vegada més restringida i emparentada amb els llinatges nobiliaris locals, i les representacions cíviques postergaven les manifestacions tradicionals dels oficis en les processons cíviques. Es tractava de tot un seguit de

\footnotetext{
${ }^{16} \mathrm{Ja}$ vàrem apuntar alguns d'aquests aspectes en Ivan MARTíNEZ ARAQUE, La casa, el taller, la botiga. Al voltant de l'habitatge de les famílies artesanes en la vila d'Alzira (segles $X I I I-X V)$, "XI Assemblea d'Història de la Ribera", Corbera, 2006. Una descripció del centre de la vila, elaborat a partir de les descripcions dels padrons de riquesa del segle XV, en Antonio MARTínEZ PÉREZ, Raquel MARTÍNEZ RUIZ, Topografía de Alzira en el siglo XV . (casco urbano), Al-Gezira, 9 (1996), pp. 71-141. Una reconstrucció completa de Pego mitjançant aquest tipus de documentacio a finals del Quatre-cents en Enric GUINOT, Javier MARTI, J. TORRÓ, Carta de poblament de Pego, 1279, Pego, 2004. Un estudi sobre la sociotopografia urbana de Lleida en Jordi Bolòs, Producció artesanal i espai urbà a Lleida als SS. XIV I XV, "XVII Congrés d'Història de la Corona d"Aragó". Barcelona, 2003, pp. 241-252. De Còrdova: Ricardo CóRDOBA DE LA LLAVE, El artesanado en Córdoba en el siglo XV: áreas de residencia y trabajo, "III Jornadas Hispano-Portuguesas de Historia Medieval", II, Sevilla, 1991 , pp. 1.253-1.275.

${ }^{17}$ Rafael NARBONA, Enrique CRUSELLES, Espacios económicos y sociedad política en la Valencia del siglo XV, "Revista d'Història Medieval", 9 (1998), pp. 193-214, insinuen que aquesta política urbanística en la ciutat de València podria correspondre igualment als interessos immobiliaris dels grups del patriciat urbà. En altres àrees, com en el nord d'Itàlia, Antonio I. PINI, La ripartizione topografica degli artigiani a Bologna nel 1294: un esempio di demografia sociale, dins Artigiani e salariati. Il mono del lavoro nell'Italia dei secoli XII-XV, Pistoia, 1984, pp. 189-224.

${ }^{18}$ I. MARTÍNEZ ARAQUE, Polítiques municipals $i$ mercat de queviures de la vila d'Alzira a les darreries del segle XIV, "Actes de la X Assemblea d'Historia de la Ribera", Antella, 2006, pp. 103-124.
} 
fenòmens, a primera vista inconnexos, que s'aguditzaren al llarg dels segles moderns ${ }^{19}$.

\section{L'OBRADOR, LA CASA I ELS INTERIORS DOMÈSTICS}

La societat baixmedieval vivia en el carrer i de portes enfora. Les vies principals eren l'escenari de la figuració simbòlica de la comunitat, de la mateixa manera que les places porticades eren el lloc de reunió dels veïns, l'escenari de les manifestacions cíviques i religioses o dels ajusticiaments exemplars. La riquesa de les façanes o les seues dimensions reflectien tant l'estatus com la riquesa patrimonial del seu habitant o l'aparença que es pretenia oferir ${ }^{20}$. Al si de les classes populars, el carrer esdevenia un apèndix més de l'habitatge i un escenari principal de sociabilitat. Els animals domèstics, els porcs o l'aviram, vagabundejaven entre els carrers de terra i el corral de la casa. Les eixides i les obligacions que requeria l'empresa familiar esdevenien diàries: al forn o la fleca, al mercat, a per aigua, a per llenya o altres materials que es recollien al bosc proper, també ho precisava el manteniment dels petits horts contigus als ravals ${ }^{21}$. Els esdeveniments que comportaven el cicle vital eren motiu de reunió per a les dones, en els parts, en l'amortallament dels difunts, els consells a les novençanes $^{22}$. mentre que uns altres espais d'encontre dels homes es trobaven en les tavernes o en el bordell ${ }^{23}$. I amb el frec diari amb els veïns, en fi, venien les disputes, les revenges i les manifestacions d'odi i de menyspreu ${ }^{24}$.

L'habitatge no era sols el lloc de replegament de la família artesana, també un dels seus mitjans de producció principals. Allà era on es prenien importants decisions de l'empresa familiar, com ara l'acceptació o no

${ }^{19}$ R. NARBONA, Memorias de la ciudad. Ceremonias, creencias y costumbres en la historia de Valencia, València, 2003 pp. 69-100. Paulino IRADIEL, Corporaciones de oficio, acción política y sociedad civil en Valencia, dins Cofradías, gremios y solidaridades en la Europa Medieval (Actas de la XIX Semana de Estudios Medievales de Estella), Pamplona, 1993, pp. 253-284.

${ }^{20}$ Un exemple el trobem en el carrer Cavallers de València, estudiat en la seua evolució en el temps per T. SIMÓ, J. TEIXIDOR DE OTTO, La vivienda y la calle. La calle de Cavallers de Valencia como ejemplo de desarrollo urbano, València, 1996. A partir de fonts pictòriques, Juan V. GARCÍA MARSILLA, La calle y el espacio público en la pintura gótica hispana, "Saitabi”, 51-52 (2001), p. 161-201.

${ }^{21}$ Un fresc respecte a la vida quotidiana en les comunitats rurals en A. FURIÓ, F. GARCIAOLIVER, Del dia i la nit. Actituds i comportaments al món rural medieval valencià, "Ullal”, 9 (1986), pp. 42-52.

${ }^{22}$ Per a època moderna, destaquem el treball de Robert MUCHEMBLED, La mujer campesina el norte de Francia (siglos XVII-XVIII), "Debats", 7 (1984), pp. 64-67.

${ }^{23}$ Malauradament, no es conserven per a aquestes dates els llibres del justícia d'Alzira i és en els processos judicials quan sentim de primera veu els protagonistes i es detalla sovint hàbits i costums quotidianes: Agustín RUBIO VELA, El procés de Sueca. La mala vida en una comunitat rural del Tres-cents, Alzira, 1988.

${ }^{24}$ En la visita pastoral a Alzira del 1386, diverșos conveïns acusen el fuster Salvador Jordà o el ferrer Ramon lo Trompador de tindre concubines. I en eixa mateixa visita se senyala que alguns dels joves destacats de la localitat, fills de notables locals com els Serrạ, Boquet o Destorrent, entraren en casa d'una dona anomenada Elvira, madura i sense maridar, "et tirando eam per crines” la van violar. Ma Milagros CÁRCEL, José Vicente BOSCÁ, Visitas pastorales de Valencia (siglos XIV-XV), València, 1996, Visita pastoral del 1386 a Alzira. 
d'algun encàrrec, i esdevenia el principal lloc d'aprenentatge d'habilitats manuals i destreses per part dels aprenents i els fills, de les quals depenia en bona part el futur del taller ${ }^{25}$. La casa esdevenia així l'oficina on es portaven uns comptes rudimentaris i s'organitzaven les activitats. Allà estaven els instruments i les ferramentes del treball artesà. En l'inventari post mortem dels béns del sastre Mateu Vidal, el 1422, se'ns descriu dintre la casa dues taules de sastre ${ }^{26}$. També en el corral, junt a l'aviram i a altres materials per a ús domèstic com la llenya, s'emmagatzemaven productes relacionats amb l'activitat artesanal: en el cas del tintorer Mateu Carbonell, el juliol del 1408, hi tenia 20 càrregues de pastell i cendra ${ }^{27}$. Dintre aquest espai situat darrere de l'habitatge, que àdhuc servia per a les necessitats fisiològiques -en algun document apareix la menció inclús a una latrina- ${ }^{28}$, podia hi haure un porxe per a guardar alguns dels nodriments de la família i les reserves per a una collita o per al pagament d'alguna sisa i els deutes: vi, cereals grossos i menuts... Ací es documenten algunes de les eines dels artesans. En l'inventari del fuster Joan Saplana, habitant del raval de l'Alquenència i mort durant el brot pesta del 1476, es diu que en el seu pati "dins hun porche de la dita cassa havia I post de fust, messa dins la paret, en la qual staven los ferraments e aynes de fuster del dit deffunt" 29 .

Però, no sols trobem els instruments del seu propi ofici, sinó d'altres tasques complementàries. Aquest últim fuster comptava amb alambins per a elaborar el vi o les calderes per a bullir els capolls dels cucs de seda. El tintorer abans esmentat tenia cardes o torns per a la llana i altres fibres vegetals. Cal tindre en compte que, a més a més, alguns dels membres més destacats de l'artesanat posseïen diverses fanecades de terra, sobretot vinyes, que servien com a complement de l'economia familiar ${ }^{30}$. A banda de tot això, la casa esdevenia la botiga per a molts artesans, on es venien els productes elaborats o on els clients es provaven els vestits, el calcer o es comprovaven els utensilis. En el testament del notari Bernat Comella, entre els deutes que afirma tindre, hi ha 25 sous dels sabaters Doménec Lázaro i Joan Vicent ${ }^{31}$. Es treballava per encàrrec i també disposaven aquests arte-

${ }^{25}$ Quant a la figura dels aprenents, que resultà ser una mà d'obra barata i assequible, Ricardo SIXTO, Los jóvenes y la incorporación al mercado de trabajo. Contratos de afermament en Valencia '(1458-1462), "II Congreso de Jóvenes Historiadores y Geógrafos", Valencia, 1993, pp. 175-187. Del servei domèstic, A. FURIÓ, Antonio J. MIRA, Pau VICIANO, L'entrada en la vida dels joves en el món rural valencià a finals de l'Edat Mitjana, "Revista d'Història Medieval", 5 (1994), pp. 75-106.

${ }^{26}$ AMA, Protocols, Protocols de Bernat Comadolins, sign. 040/24, 17-IV-1422.

${ }^{27}$ Ibídem, Protocols de Bernat Llorenç, sign. 040/14, 16-VII-1408.

${ }^{28}$ Ídem, sign. 040/11, 19-X-1400.

${ }^{29}$ AMA, Pergamins Comuns, sign. 011/247.

${ }^{30}$ Resseguint només els casos dels inventaris post mortem d'artesans esmentats, tenim que els tintorers Lluís Fuster i Mateu Carbonell posseien un camp de vinyes cadascú, el primer en la partida de Benirrabea i l'altre en l'Alborg1, i el sastre Mateu Vidal tenia un tros de vinya en l'Almúnia i fanecada i mitja de terra en la partida del Barralbeb. Aquest component de diversificació econòmica de les famílies ha estat un element que ha destacat la historiografia en els últims anys, Ch. DYER, La historia de los niveles de vida en Inglaterra, 1200-1800. Problemas y enfoques, "Historia Agraria", 16 (1998), pp. 101-117.

${ }^{31}$ AMA, Protocols, Protocols de Bernat Llorenç, sign. 040/14, 4-VII-1408. 
sans d'alguns estocs de productes. En l'entrada, en l'espai a la vista del carrer, el fuster Saplana tenia, junt als diversos bancs de fuster on treballava $\mathrm{i}$ altres utensilis, unes posts per al forn $\mathrm{i}$ peces per a les eines del camp -fins a 46 dentals d'aradres de carrasca o 41 cametes-.

A banda de les estances ja esmentades, i situades normalment en la planta baixa, la casa podia tenir una planta superior, sostinguda amb cabirons a mode de biguetes i jàsseres o pilars d'obra. S'hi podia accedir per una escala de fusta i servia de cambra. Aquesta comptava amb una sèrie de màrfegues de palla, llana o plomes, i podien separar-se les habitacions per mitjà de cortines. En el dormitori principal, el matalaf normalment descansava sobre una sèrie de posts de fusta, cinc o sis. El mobiliari el completaven petits armaris amb caixons o cofres on es guardava la roba del matrimoni o de la llar, ací predominava el lli en els llençols o tovalloles, la resta de l'aixovar i els pergamins on venien anotades les possessions de la família. En la cambra hi havia en gerres, orons o sacs algunes de les collites i altres reserves d'aliments ${ }^{32}$. En suma, els interiors domèstics dels artesans, i d'altres grups socials, se'ns mostren molt modestos i sobris amb objectes aprofitats fins a l'extenuació, i més que pel nombre dels mobles destacaven per la varietat dels teixits, cosa que no descartava que s'hi trobara algun objecte de luxe o autèntics arsenals d'armes ${ }^{33}$. Estem al davant, doncs, d'un escenari que englobava diverses realitats, realment vulnerable i no exempt de tensions, en què si fallava alguns d'aquests elements es podria comprometre la continuitat de l'estructura familiar.

\section{LES DONACIONS I LES HERÈNCIES, LA FAMÍLIA I LA CASA}

Les fonts privilegien aquestes famílies nuclears. Tanmateix, el predomini de la casa unifamiliar no ha de fer-nos passar per alt que existiren altres tipologies d'habitatges. L'hostaler alzireny Esteve Folc nomenà procurador a un veí de Gandia per a recuperar d'un pintor d'aquesta vila, Joan Illet, 21 s. i 4 diners per l'allotjament i diverses provisions ${ }^{34}$. Només tenim

\footnotetext{
${ }^{32}$ Sens dubte, els inventaris post mortem, realitzats pels notaris a instància d'hereus o marmessors d'un difunt sobre els béns d'aquest, constitueixen una font privilegiada per endinsarse en les cases de l'artesanat de l'època. Això no obstant, presenten notables omissions i insuficiències, com ara les parques descripcions de l'espai. Han estat els modernistes, en disposar d'un major nombre de fonts, els que més han reflexionat sobre aquest tipus de documents, Hortensio SOBRADO CORREA, Los inventarios post-mortem como fuente privilegiada para el estudio de la Historia de la cultura material en la Edad Moderna, "Hispania", 215 (2003), pp. 825-861, i Xavier LENCINA PÉREZ, La historia des del subjecte. Inventaris post mortem. microhistòria i cultura material a la Barcelona moderna, "Estudis històrics i documents dels Arxius de Protocols", XXI (2003), pp. 199-242.

${ }^{33}$ En la casa del tintorer Mateu Carbonell, trobem inventariats un canelobre, una ampolla, una copa de vidre, dos collars d'argent i un de corall, a més d'una llança gran, unes altres quatre més menudes, un dard i dos adargues; en l'inventari de béns del sastre Bernat Vidal S'hi descriuen, en una de les dos cases que posseïa, un drap "on és pintada la istòria [sic] de la Verge Maria”, la llança, el dall i l'espasa corresponent; o, en el de Lluís Fuster, hi ha quatre llances, cinc dards, una adarga i una llança llarga.

${ }^{34}$ Arxiu de Protocols del Patriarca de València, Protocols notarials, Protocols d'Innocent de Moya, sign. 25172, 28-XI-1420.
} 
referències indirectes de persones que van haver de llogar alguna de les habitacions dels diversos hostals que hi havia a la vila i als ravals, però. El 1400, l'hostaler Arnau Castelló va exigir a un habitant oriünd de Terol, el cardador Garcia Gonçal, 20 s. per la pensió de 24 nits d'haver-hi pernoctat ell, la dona $\mathrm{i}$ els tres fills, $\mathrm{i}$ per diversos pintes que li facilità, $15 \mathrm{~s} .{ }^{35}$. Cal pensar, també en la manufactura, que hi eren presents sectors econòmics estacionals que requerien d'abundant mà d'obra en etapes concretes de l'any i la població immigrant de caràcter temporal segurament feia servir algunes d'aquestes cambres. ${ }^{36} \mathrm{Al}$ darrere d'aquestes llacunes hi havia també un cert component ideològic, en considerar veïns només els homes adults casats, els caps de família cristians, que posseïen algun tipus de bé immoble, en front dels mers habitants que no contribuïen a les arques municipals ni tampoc tenien dret a participar en el consell general. ${ }^{37}$

Les mencions a l'arrendament d'immobles són escasses igualment. Els jurats d'Alzira pagaren, el 1399, 18 d. cada dia per l'allotjament d'un eclesiàstic en ca Bernat Ximeno, que devia escriure un llibre "divinal e scolar" 38 . Davant els notaris el que es posa per escrit són, sobretot, les transaccions i les cessions de la propietat o la seua possessió. A diferència de les grans ciutats, on sí abunda el contracte de lloguer per als immobles o només per alguna estança, en les viles aquest s'amagaria darrere les relacions quotidianes de confiança o de dependència. A grans trets, en la documentació el que es privilegia és la família com a unitat elemental de la fiscalitat i els titulars de l'habitatge unifamiliar, en ser una font de renda.

La família nuclear, en fi, es tractava de la cèllula de reproducció bàsica de la societat, constituïda pel marit, la muller, els fills fadrins i els aprenents o servents domèstics sota un mateix sostre. Amb l'establiment d'aliances, per mitjà de certes estratègies familiars, els fills accedien al matrimoni i constituien una nova unitat independent. En la casa que deixà el fuster Bernat Cenquirles a sa muller com usufructuària treballava el fill d'ambdós, Joan, ja casat el $1408^{39}$. En efecte, això no impedia que hi haguessen casos de cohabitació de pares, fills, nores o gendres, que es poguessen fer divisions internes en les cases o que els germans ja casats treballassen en comú en l'empresa dels progenitors.

\footnotetext{
${ }^{35}$ AMA, Protocols notarials, Protocols de Bernat Sabater, sign. 040/22, 21-XII-1400.

${ }^{36} \mathrm{La}$ presència dels jornalers en les ordenances de la vila són una constant, sovint amb una vinculació quasi directa amb la delinqüència. Però, també hi ha d'altres referides a l'ordenació del treball, sempre des d'un punt de vista més bé moral, com ara es prohibia en èpoques intensives de treball que els almasserers molgueren olives els diumenges el gener del 1367, Libre dels diverses estatuts, est. 52. Sobre la diversitat de famílies i d'habitatges en època moderna, Raffaela SARTI, Vida en familia. Casa, comida y vestido en la Europa moderna, Barcelona, 2003.

${ }^{37}$ Sobre aquesta distinció, a voltes molt vaga tot i que comuna a la Corona d'Aragó, José Á. SESMA, La población urbana en la Corona de Aragón (siglos XIV-XV), dins Las ciudades urbanas en la España medieval. XXIX Semana de Estudios Medievales, Pamplona, 2003, pp. 151-193.

${ }^{38}$ AMA, Llibres dels actes dels jurats e consell, sign. 03/7, fulls solts.

${ }^{39} \mathrm{Ib}$., Protocols notarials, Protocols de Bernat Llorenç, 040/14, 24-VIII-1408.
} 
I no sempre la reproducció de la família era l'única via de reproducció social del grup. L'hostaler Guillem Fenoll casà el seu fill Antoni Fenoll, un ric sastre del raval del Barralbeb, amb una filla de la família dels Osca de Guadassuar ${ }^{40}$. Els llinatges amb els quals s'acordaven els matrimonis o les activitats que desenvolupaven els fills no sempre coincidien amb la professió dels pares. El sastre Bartomeu Vidal maridà la seua filla Jauma amb un notari, Gerard Despuig, el qual va morir pel $1400^{41}$. Allò important, doncs, era mantindre en cada successió l'estatus socioeconòmic de la família, en emparentar amb aquells que disposaren d'una riquesa o prestigi semblant al si de la comunitat ${ }^{42}$.

Evidentment, una de les principals funcions de la família era la transmissió del patrimoni. El règim hereditari valencià era igualitari entre els fills, encara que el testador podia privilegiar a uns respecte a la resta, sempre que no s'alteràs la legítima; l'erosió i dispersió dels béns familiars era, doncs, un dels problemes que es presentaven aviat ${ }^{43}$. Aquesta transmissió es produïa, de vegades, en diverses fases, tant en la constitució de les noves cèl-lules conjugals com en el moment de la mort dels pares. Un dels mecanismes era el sistema dotal, pel qual les filles quedaven excloses formalment de l'herència. El matrimoni de Margarida i el paraire Antoni Casalills arribà a nomenar un representant legal per recuperar dels pares d'aquesta, l'habitant a Ternils Bartomeu Barral, els $290 \mathrm{~s}$. que restaven per abonar pel seu dot el $1399^{44}$.

Bo i que el gros de les transmissions es produïa en el moment de fer efectiu el testament, això no excloïa, en efecte, que al llarg del cicle vital dels fills es donaren avanços de l'herència. Així, el 1405 el sastre Ramon Vidal i Benvinguda, filla d'Antoni Saidí de Cogullada, van rebre dels pares del primer diverses terres i un obrador en el carrer Major ${ }^{45}$. Si bé existien altres fórmules a banda de la separació de béns en el matrimoni, com la comunitat de béns o germania, tant el dot, que esdevindrà hegemònic, com les donacions pel matrimoni o de pares a fills -donationes inter vivos- coadjuvaven a posar en marxa les noves unitats familiars.

Això no obstant, no sempre el gruix dels patrimonis de les famílies el constituïen els béns heretats o transmesos. Per adquirir més propietats, eixamplar les ja existents o assegurar la viabilitat de l'empresa familiar,

${ }^{40} I d$. , Protocols de Ramon Sabater, sign. 040/22, III-XII-1400.

${ }^{41}{ }_{1}^{\prime} d$., Protocols de Bernat Llorenç, sign. 040/5, 22-II-1379.

${ }^{42}$ José Ma CRUSELLES, Movilidad social y estrategias familiares en el medio urbano bajomedieval, "Millars. Geografia i Història", XIII (1990), pp. 87-94. Hi havia una tendència semblant entre els artesans d'època moderna en algunes viles catalanes, Jaume TORRAS Gredins El trabajo a través de la historia. Actas del II ${ }^{\circ}$ Congreso de la Asociación de Historia Social (S. CÁSTILLO, coord.), Madrid, 1996, pp. 171-179.

${ }^{43}$ A. FURIÓ, Reproducción familiar y reproducción social: famila, herencia y mercado de la tierra en el País Valenciano en la baja Edad Media, dins Tierra y familia en la España meridional, siglos XIII-XIX. Formas de organización doméstica y reproducción social (F. GARCÍA GONZÁLEZ, ed.), Múrcia, 1998, pp. 25-43.

${ }^{44}$ AMA, Protocols, Protocols de Bernat Llorenç, sing. 040/10, 11-VI-1399.

${ }^{45}$ Ib., sign. 040/3, 12-VIII-1405. 
s'havia de recórrer necessàriament al mercat. A. Furió ha posat de manifest que el mercat de la terra, en el cas de la Ribera, va dominar aclaparadorament com a via principal d'accés a les propietats rústiques, molt per damunt de les transmissions en forma de donacions dins les mateixes famílies ${ }^{46}$. En l'estudi dels béns immobiliaris urbans dels artesans, tot i que la mostra l'hem realitzada a partir dels protocols notarials i no sobre les dades més abundants i exhaustives dels padrons de riquesa que arranquen del 1450, els percentatges són pràcticament idèntics als que ofereix l'autor: un $88 \%$ dels 64 casos analitzats a finals del segle XIV i la segona dècada del XV corresponen a compravendes. En conseqüència, les vivendes, a banda d'un valor d'ús, tenien un fort valor de canvi.

\section{EL MERCAT IMMOBILIARI EN LA VILA}

El mercat de béns immobles urbans es va mostrar realment molt precoç i dinàmic en terres valencianes, gairebé el trobem actiu l'endemà de la conquesta. En els territoris ocupats, les donacions de parcel·les agràries anaven acompanyades normalment de cases i es produí una distinció social amb aquells personatges que tenien una major respectabilitat d'origen, cosa que implicava unes dotacions més grans ${ }^{47}$, sense oblidar les usurpacions i irregularitats que es donaren els primers anys de la colonitzación ${ }^{48}$. Els nouvinguts podrien rebre terres i cases franques, però molts s'establiren a cens tant del rei, dels senyors en els llocs de senyoria, de les institucions eclesiàstiques com dels individus més destacats de la comunitat. A un mateix temps, aquests darrers disposaven de millors condicions per adquirir altres béns de gent que acabà per no establir-se o que va entrar en situació de vendre els seus immobles. En definitiva, les rendes i els beneficis generats pels habitatges esdevingueren un dels ressorts de l'oligarquia local ja en el segle XIII $i$ inicis del XIV, i continuaren sent-ho, malgrat els moviments d'ascens social de llinatges i de desclassament que s'hi van produir ${ }^{49}$.

Un altre factor que influí decisivament en el desenvolupament d'aquest mercat foren els avantatges que es donaren per tal de propiciar l'atracció d'immigrants, i, entre ells, estaven tant les donacions de cases

\footnotetext{
${ }^{46}$ A. FuRIÓ, El mercado de la tierra en el País Valenciano a fines de la Edad Media, "Hispania", 191 (19395), pp. 887-919.

${ }^{47} \mathrm{~A}$ tall d'exemple, en les donacions fetes arran de la construcció de la Séquia Reial a partir del 1269, Robert I'. BURNS, Diplomatarium of the Crusader kingdom of Valencia. The registered charters of its conqueror Jaume I, 1257-1276, doc. 514, $1.023,1.240,1.2450$ 1.481.

${ }^{48} \mathrm{El} 1246$, Jaume I hagué de sancionar la situació donada al terme d'Alzira i va reconéixer a qui es va apropiar indegudament d'algunes terres de musulmans com a senyors directes, J. TORRÓ, "Guerra, repartiment i, colonització al regne de València (1248-1249)" dins Repartiments medievals a la Corona d'Aragó (E. GUINOT, J. TORRÓ, eds.), València, 2007, pp. 201276

${ }^{49} \mathrm{On}$ es disposa de documentació notarial o del justícia en el segle XIII ja es perceben trets d'un actiu mercat. També en el terme veí de Corbera, el canvi de mans de les primeres donacions fou realment vertiginós, S. VERCHER, Corbera en temps de Jaume I, Corbera, 2009, esp. pp. 50-83.
} 
franques com el seu establiment en règim d'emfiteusi, amb uns censos relativament baixos i estables, que permetien la total disposició dels posseïdors per vendre, alienar o transmetre al seu albir, barata el pagament del lluïsme -el $10 \%$ del valor de la transacció- i de la fadiga o dret de preferència en la compra per part del propietari directe en el cas de l'emfiteusi.

Això no obstant, ben al contrari del que ha succeït en altres zones, al País Valencià no comptem pràcticament amb estudis sobre el mercat immobiliari urbà per als segles baixmedievals, malgrat la relativa riquesa de les fonts documentals ${ }^{50}$. Una de les principals raons possiblement rau en què els documents notarials són poc generosos en detalls: en els contractes de compravenda, d'alienació, de permuta, etc., rarament ens apareixen dades quant a les dimensions dels béns en qüestió i les referències a la seua ubicació solen limitar-se a les afrontacions amb els posseïdors de vivendes pels tres costats de la casa en aquell moment. Fins i tot, en ocasions no sabem amb certesa de quants immobles o de quines parts se'ns parla ${ }^{51}$. Tot plegat ha d'obligar-nos a interrogar els documents sobre per què diuen el que diuen i no esmenten altres elements, o, en altres paraules, tractar de revisar les lògiques pròpies d'aquell mercat i la dels actors que el movien.

A l'igual que ocorria amb la terra, el de les cases es tractava d'un mercat fortament personalitzat $\mathrm{i}$ allò que veritablement importava eren les relacions que es fixaven entre les parts, això és, com s'anava a abastir l'import estimat. Un segon element que es considerava era l'anotació de la part corresponent del cens al propietari directe si esqueia. I això amb independència del nombre d'immobles o de la part d'aquest que s'adquiria ${ }^{52}$. Eren circumstàncies, doncs, que condicionaven el preu final i també estava marcat, en un àmbit certament limitat com era el sòl urbà, per l'oferta i la demanda, i en especial en les zones més atractives per als negocis per als artesans que disposaven del producte final. Hi influien òbviament elements relatius a les dimensions, qualitat de l'edifici, o béns mobles que es podrien

\footnotetext{
${ }^{50}$ Per a València, cal destacar el recent treball, dins el monogràfic dedicat al mercat immobiliari urbà en diferents paîsos europeus, de P. IRADIEL, Mercado inmobiliario, crédito y crecimiento urbano medieval en Valencia, dins Mercado inmobiliario y paisajes urbanos en el Occidente europeo: siglos XI-XV. XXXIII Semana de Estudios Medievales, Pamplona, 2007, pp. 377-415. La historiografia andalusa ha produït alguns treballs en aquest sentit. A. CORANTES DE TERÁN, Propiedad y mercado inmobiliario en la Edad Media: Sevilla, siglos XIII-XVI, "Hispania", 169 (1988), pp. 493-527, i també en Margarita CABRERA Oligarquía urbana y negocio inmobiliario en Cordoba en la segunda mitad del siglo XV, "Historia, Instituciones, Documentos", 20 (1993), pp. 107-126.

${ }^{51}$ Es reduêix ben bé sempre a una paraula en plural, ja siga en català, "cases", com en llatí, "domibus". Per altra banda, en altres àrees peninsulars també es designava en plural els immobles, Maria C. FALČ̃̃O, Luis M. DUARTE, La construction courante au Portugal à la fin du Moyen Age et au début de l'Europe Moderne, dins L'edilizia prima della revoluzione industriale, seccoli XIII-XVIII. Atti della "Trentaseiesima Settimana di Studi" (S. CAVACIOCCHI, ed.), Prato, 2005, p. 587-624. Al respecte, J. Torró interpreta que "casa" generalment es referia a l'estança que generava l'espai entre els murs de carrega o crugies, en La formació d'un espai feudal, ob. cit., pp. 160-177.

${ }^{52} \mathrm{La}$ transacció de sols una part d'un immoble no era infreqüent. En un testament ja citat, Bernat Comella deixa al seu nebot Doménec els obradors que es troben davall de les cambres donades a la muller d'aquell, "e puxa fer e estar e stiga en los dits obradós, no contrastant la lexa feta a la dita muller mia del estatge de les dites cases e obradors."
} 
incloure en la venda, elements que no sempre podem valorar per la manca de descripcions.

Ara bé, en la fixació dels preus resultaven definitius la condició jurídica de l'immoble, si era franc o a cens, i a quines càrregues es trobava sotmés, açò és, si en la transacció es traspassaven els censals o els deutes que la família venedora havia adquirit posant com a aval el bé en qüestió. Això emmarca les enormes diferències que hi trobem a Alzira: des de $53 \mathrm{~s}$. $4 \mathrm{~d}$. per la compra d'unes cases en la vila fins a $1.400 \mathrm{~s}$. en el raval de l'Alquenència a les acaballes del segle XIV i primeries del XV. En aquest sentit, el censal va irrompre en el conjunt de la societat valenciana durant la segona meitat del segle XIV i, sens dubte, va contribuir a animar, i condicionar en part, el mercat dels béns immobles urbans.

El censal privat es va estendre ràpidament gràcies a la seua plasticitat, i en un dels seus vessants funcionà com una espècie de crèdit hipotecari, en vincular tota o una part de la venda d'un bé immoble amb el pagament d'una renda. El manyà Jaume Salom, com a tutor d'una néta seua i filla del paraire difunt Berenguer Salom, vengué el 1413 en pública subhasta les cases i obradors en la vila que havia d'heretar la xica. Els va comprar un altre paraire, Alfons Martínez, immigrant castellà i considerat "habitant”, per 600 s. En el moment de la transacció solament n'aportà 400: 340 s. eren pel preu d'un censal que li pagava la vídua del fuster Pere Miró, que ara cedia, i 60 s. oferts pròpiament per Alfons, qui en la Quaresma vinent prometia abonar la resta ${ }^{53}$.

De fet, més que d'una circulació monetària o d'una sola paga en l'acte, el mercat immobiliari es movia, com passava amb d'altres presents en les viles, per una veritable circulació de l'endeutament, ja fos de censals o de fraccions de censals, que es traspassaven amb uns altres deutes en cada compravenda. I si el comprador incomplia els terminis de pagament fixats $i$ continuava devent una quantitat, s'acabava signant un altre censal per la quantitat a restituir. El 1403 el sastre Joan Martí hagué de signar un violari de $580 \mathrm{~s}$. per abonar els 280 que encara restaven per pagar pel preu d'una casa $^{54}$. El censal i les seues múltiples variants es configuraren com una càrrega més, afegida a les múltiples a les quals estava sotmesa el conjunt de les famílies. ${ }^{55} \mathrm{Cal}$, emperò, matisar la seua incidència. Les quantitats prestades normalment no eren gens menyspreables per a les economies de la majoria dels artesans, en situar-se la mitjana en més de 400 s. ${ }^{56}$ Per tant,

${ }^{53}$ AMA, Protocols, Protocols de Bernat Llorenç, sign. 040/15, 13-XI-1413.

${ }^{54}$ APPV, Protocols, sign. 22.484, 11-X-1403.

${ }^{55}$ J.V. GARCía MARSILla, Vivir a crédito en la Valencia medieval. De los orígenes del sistema censal al endeudamiento del municipio, València, 2002, i A. FuRIÓ, Crédito y endeudamiento: el censal en la sociedad rural valenciana (siglos XIV-XV), dins Señorío y feudalismo en la península Ibérica, ss. XII-XIX (E. SARASA, E. SorIANO, eds.), Saragossa, 1993, pp. 501-534.

${ }^{56}$ Sobre l'artesanat a Alzira i la Ribera, I. MARTínez ARAQUE, En els orígens de la indústria rural. Artesanat i manufactura a Alzira i la Ribera (segles XIII-XV), Treball d'investigació inèdit, València, Universitat de València, 2008. 
solament estava a l'abast d'aquells artesans que podien oferir certes garanties de solvència.

En relació amb els artesans d'Alzira, hem pogut documentar al voltant d'una seixantena operacions de compravenda de propietats immobiliàries entre 1381 i 1416 , tant de cases com de cases-obradors relacionades amb els artesans. Dissortadament, no sempre sabem a quants immobles en concret es fa referència, en conseqüència només ho anotem simplement com a operacions. Així doncs, el valor del total registrat ascendeix a més de $26.000 \mathrm{~s}$., una quantitat equivalent al que recaptava la batllia local en un any o un poc menys de la meitat d'allò que movia el mercat de la terra en tot el terme municipal per aquells decennis ${ }^{57}$. I és que normalment la casa era cara en el centre urbà. Els valors mitjans se situaven entre 300 i 600 s., més del que correspondria als ingressos en brut d'un salari no qualificat a l'any d'un home adult o el dot de la filla d'un petit artesà, i en les zones més cotitzades, com el carrer Major, no eren inusuals les xifres que superaven els $1.000 \mathrm{s.}^{58}$.

Un dels elements que expliquen el funcionament d'aquest mercat corresponia a la situació del venedor, molt a sovint obligat per les circumstàncies o per les necessitats. El tutor dels fills del tintorer que hem vist en un inventari anterior, Mateu Carbonell, ha de vendre les cases i el tint uns pocs anys després de l'òbit d'aquest. Efectivament, és freqüent trobar en aquestes vendes a algunes vídues o administradors dels hereus menors d'edat, a famílies que s'havien vist trencades per la mort del cap de família i que la seua situació s'havia vist alterada de cop i volta i ja no podien sostenir les empreses familiars. Jauma, vídua del fuster Jaume Torroja, va vendre unes cases en el raval de l'Alquenència el 1399 per 200 s. i comprà unes altres per un preu inferior, 121 s., a una altra vídua ${ }^{59}$. Andreu Argenter, ferrer, va adquirir unes cases en el raval de l'Alquenència d'un hostaler que llavors habitava a Xàtiva per 165 s. el $1381^{60}$. És a dir, del mateix mode tenim a emigrants que s'havien vist empesos a vendre o malvendre les seues possessions, com també a artesans ofegats pels deutes i que optaren

${ }^{57}$ En la quinzena del $1369-1384$, les transaccions de propietats rústiques muntaren uns 34.000 s., vid. A. FURIÓ, El mercado de la tierra, ob. cit. Les dades les hem recollides de la documentació notarial; no cal dir que es tracta de mostres aleatòries per haver-se conservat només una part dels documents de l'època.

${ }^{58} \mathrm{~A}$ València, el cost de les vivendes corrents se situava entre els 1.000 i $2.400 \mathrm{~s}$. a finals del Tres-cents; tanmateix, el lloguer arribava a un $60 \%$ dels casos en els barris de major concentració artesanal, com Sant Joan del Mercat o. Santa Caterina, amb uns preus que estaven en torn els $200 \mathrm{~s}$. P. İRADIEL, Mercado inmobiliario, crédito ob. cit., pp. 405-406. Gràcies a la major documentació notarial conservada en la capital des del segle XIII, aquest autor ha pogut obsẹvar que hi hagué una distinció entre la propietat dẹl solar l de l'immoble, a l'igual que al Laci, Etienne HUBERT, Considérations sur la propiété immobilière dans les villages du Latium au Moyen Age, dins Le village medieval et son environnement (L. FELLER, P. MANER, F. PIPONNIER, eds.), París, 1998, pp. 131-144.

${ }^{59}$ AMA, Protocols, Protocols de Bernat Llorenç, sign. 040/10, 3-III-1399.

${ }^{60} \mathrm{Ib}$., sign. 040/6, 3-I-1381. 
per cedir els censals contrets a canvi d'un preu raonable per l'immoble ${ }^{61}$. O parlem de posada en el mercat de béns mitjançant subhastes per l'amenaça d'embargament.

El mercat de les cases responia a moltes i diverses raons, com hem tractat d'apuntar, d'ací que hi concorregueren un elevat nombre d'artesans. Al remat, es tractava d'un mode de recomposar el patrimoni familiar afectat per la transmissió hereditària. I no era inusual les adquisicions d'habitatges annexos al dels compradors per ampliar-los: Pere Gonçal, fuster de la vila, vengué al teixidor Gil Caro unes cases franques per 600 s. el 1400, i uns dies després comprà unes altres en la fusteria per un preu de 1.800 s., que enfrontaven $\mathrm{amb}$ altres immobles que ell tenia ${ }^{62}$. Fins i tot, per completar l'herència d'un dels successors, entre els hereus es procedia a formular-la com una venda: si un dels fills havia decidit ocupar el bé immoble dels progenitors comprava a la resta de germans la part que no cobria el valor de l'herència. Així, Barcelona, Joana i Ramon Arnau vengueren al seu germà, el teixidor Guillem Arnau, unes cases en la vila que pertanyien a sa mare difunta, a cens de $12 \mathrm{~s}$. a l'almoina de la seu de València, per $120 \mathrm{~s}$. el $1408^{63}$. A més a més, amb la compra de cases es podia garantir el traspàs de certs immobles cap a les noves empreses familiars dels fills, indefugibles per acordar aliances familiars. El 1407 Arnau Bornissó, paraire, donà com a dot a la seua filla Gentil per al seu matrimoni amb Jaume Aimeric, habitant en el raval de l'Alquenència, $800 \mathrm{~s}$,, el qual incloïa diversos béns, entre ells unes cases en el raval. Prèviament, el 1400, s'indica que Arnau havia comprades unes altres pagadores d'un cens de $12 \mathrm{~s}^{64}$.

Els beneficiaris indirectes de tot açò, bo i que òbviament també hi participaren de forma activa en les compravendes, eren els propietaris últims d'algunes d'aquestes cases: membres de la cavalleria i l'oligarquia local, com els Roca o els Destorrents, a més d'institucions eclesiàstiques, entre elles els benifets i aniversaris instituïts per eixes famílies de l'elit local, els quals assignaven una sèrie de rendes per al manteniment de les seues capelles privades en les dues esglésies principals de la localitat. I això sense comptar les pensions dels censals sobre determinats béns immobles. Altrament, el consell de la vila havia adquirit el privilegi de poder recaptar tant els censos com els lluïsmes de les propietats reials durant aquests anys, amb la qual cosa, i a canvi d'una quantitat anual fixada, els arrendataris

\footnotetext{
${ }^{61}$ Una aproximació a l'immigració en la Ribera en I. MARTÍNEZ ARAQUE, Immigració $i$ mobilitat poblacional en la Ribera del Xúquer en la baixa Edat Mitjana, dins Els processos migratoris a les terres de parla catalana. De l'êpoca medieval a l'actualitat, "VIIIe Congrés de la CCEPC", Valls, 2009, pp. 109-123.

${ }^{62}$ AMA, Protocols, Protocols de Bernat Llorenç, sign. 040/11, 7-I-1400.

${ }^{63} \mathrm{Ib}$., sign. 040/15 , 25-X-1408. III-1407.

${ }^{64} I$ Id., Protocols de Ramon Sabater i de Bernat Llorenç, sign. 040/22 i 13, 13-XI-1400 i 7-
} 
-justament on destacaren aquests prohoms- es garantien un cert marge de guanys entre la diferència d'allò arrendat i allò recaptat ${ }^{65}$.

Aquest mercat assoleix en la vila, doncs, una destacable complexitat: per la freqüència de les seues operacions, el volum abastat, la distinció entre propietat i possessió, el nombre d'actors implicats o el desenvolupament dels mecanismes de crèdit. Fins i tot, trobem a autèntics professionals que actuaven com una mena de corredors immobiliaris. Pere Amat, veí d'Alzira, nomenà com a representant legal a Pere Rubiols, tender, per a vendre a qui cregués oportú certes cases el $1407^{66}$. El que suposava que hi havia intermediaris que comptaven amb uns bons coneixements de les oportunitats del mercat i amb molt bona informació al respecte. Val a dir que no sols els trobem en el de les cases, també en el de la terra i en el de les instal·lacions de transformación ${ }^{67}$.

Per un altre costat, entre els compradors més significatius de l'artesanat i que participaren activament en aquest mercat immobiliari, trobem a aquells que gaudien d'una bona posició dins el seu ofici. El fusters Pere Alboreda, el sastre Bartomeu de la Mata o el paraire Bartomeu Adzebró pertanyien a diverses generacions destacades del mateix ofici, tots ells foren consellers en el consell general de la vila alguns anys, també van posseir diversos immobles, en cases o en terres, i participaren en les seues compravendes. Les rendes aparellades a aquestes propietats garantien uns ingressos ordinaris, era una manera segura d'estalvi, i permetien de carregar al seu temps altres censals, posant com a garantia els béns. Òbviament, en algunes ocasions el negoci immobiliari oferia uns beneficis elevats en terminis no massa llargs, en ocasió de compres de cases venudes forçosament i la seua revenda a un preu més elevat ${ }^{68}$. I és que aquests menestrals no invertien només en un sol sector, sinó en diversos, cosa que permetia reduir els riscos ${ }^{69}$. En definitiva, es tractava de falcar amb unes bases més sòlides la trajectòria de les famílies, de canviar alguns dels ressorts d'aquestes amb activitats comercials, rendístiques o creditícies com un pas necessa-

${ }^{65} \mathrm{El} 1399$ els arrendaren Antoni Cisteró, sabater, i Bernat Ximeno, que fou corredor públic, durant 5 mesos per $2.920 \mathrm{~s}$., AMA, Llibre dels actes dels jurats e concell, sign. 03/5 29-XII-1398. Sobre els arrendaments de tributs, P. VICIANO, Regir la cosa pública: prohoms poder local a la vila de Castelló (segles XIV-XV), València, 2008.

${ }^{66}$ AMA, Protocols, Protocols de Bernat Llorenç, sign. 040/13, 18-IV-1407.

${ }^{67}$ Joan Domínguez, doctor en lleis de València, tenia cap al 1400 diverses propietats en el terme d'Alzira -un molí, un forn i una taula de carnisseria-i va delegar en Joan Seguer, draper, perquè gestionara els seus béns, $i b$., 040/11, 23-IX-1400.

${ }^{68} \mathrm{El} 1379$, Ramon de Palau, habitant del raval de l'Alquenència, vengué a Pere Company, habitant d'Alcoi, un hostal en el raval, sota el domini del convent de Sant Agustí amb 8 s. de cens per 2.000 s. El 1403 és venut amb el mateix preu del 1396: 3.005 s. Id., sign. 040/5 12, 20 -IV-1379 i 2 -II-1403.

${ }^{69} \mathrm{Al}$ respecte d'aquesta multiplicitat d'operacions d'alguns artesans, el 1389 el vicari de Sueca Pere Tovia afirma que un fuster de la comunitat, Jaume Valent, va practicar usura a l'hora de prestar blats i draps. Visitas pastorales de Valencia, Visita pastoral del 1388-1389 a Sueca. Sobre la diversificació d'activitatats econòmiquẹs: A. FURIó, Las élites rurales en la Europa medieval y moderna. Una aproximación de conjunto, dins En el lugar del campesino. En torno a la obra de Reyna Pastor (A. RODRÍGUEZ, ed.), Madrid, 2007, pp. 391-421; E. CRUSELLES, Los mercaderes de Valencia en la Edad Media (1380-1450), Lleida, 2001. 
ri per relacionar-se i emparentar amb altres membres d'estrats socials superiors.

\section{HABITATGES I FAMÍLIES}

Arran de la colonització feudal, amb l'aprofitament de les infraestructures anteriors, l'eixamplament del territori conreat al llarg del segle XIII i XIV i les possibilitats que s'albiraven, acudiren contingents de població en una vila naixent, com era el cas d'Alzira, en què s'oferien possibilitats per què un sector ingent de colons es dedicàs a cobrir alguns dels béns bàsics que es requerien. Açò es va traduir en un centre urbà cada volta més atapeït i en l'activació d'un mercat de les propietats immobiliàries urbanes des de ben prompte. Igualment, es forjà una oligarquia local, gràcies en part a la seua major concentració de béns i propietats, que va participar en aquell mercat en una posició preeminent.

Es tractava indubtablement d'un dels principals actors del mercat immobiliari, ja que era un àmbit estable per als capitals de l'elit vilatana $\mathrm{i}$ que permetia la percepció de rendes, açò és, esdevenia un dels fonaments de les seues bases patrimonials i del seu prestigi social. Però, no solament hi participava l'oligarquia. Paral-lelament a això, i com a resultat de certa especialització amb el creixement econòmic del Tres-cents, un sector de l'artesanat més acabalat va arribar a protagonitzar una part de l'organització de la producció, i per a garantir-se certes seguretats diversificaren les seues inversions, ja fos en l'esfera dels intercanvis però també en les propietats 0 el crèdit. Per a aquests últims professionals resultava, al capdavall, un pas necessari per impulsar els mecanismes d'ascens social.

Més enllà d'això, la casa era un dels mitjans de producció essencials per a bona part de la menestralia en molts aspectes, malgrat la seua escasa capitalització. En front de l'erosió patrimonial que afectava a cada recanvi generacional en el moment de la transmissió, el mercat immobiliari es va configurar com un mecanisme reequilibrador de l'empresa i el patrimoni familiar, tant com si es tractàs d'adquirir propietats com per desferse'n. Tanmateix, l'artesanat amb menys mitjans va acudir en condicions adverses cap a l'intercanvi, en moments de vulnerabilitat o de necessitat, sovint com a venedors. Ben mirat, i des de diferents vessants, el mercat immobiliari es convertí en un dels diversos elements que va contribuir a una progressiva jerarquització de la societat valenciana baixmedieval també al si del grup artesanal.

Data de recepció de l'article: setembre 2009.

Data d'acceptació i versió final: abril 2010 


\section{ANNEXOS}

\section{ANNEX I}

La vila i els ravals d'Alzira amb la ubicació de les principals vies $i$ barris (cap al final del segle XIV i el començament del XV)

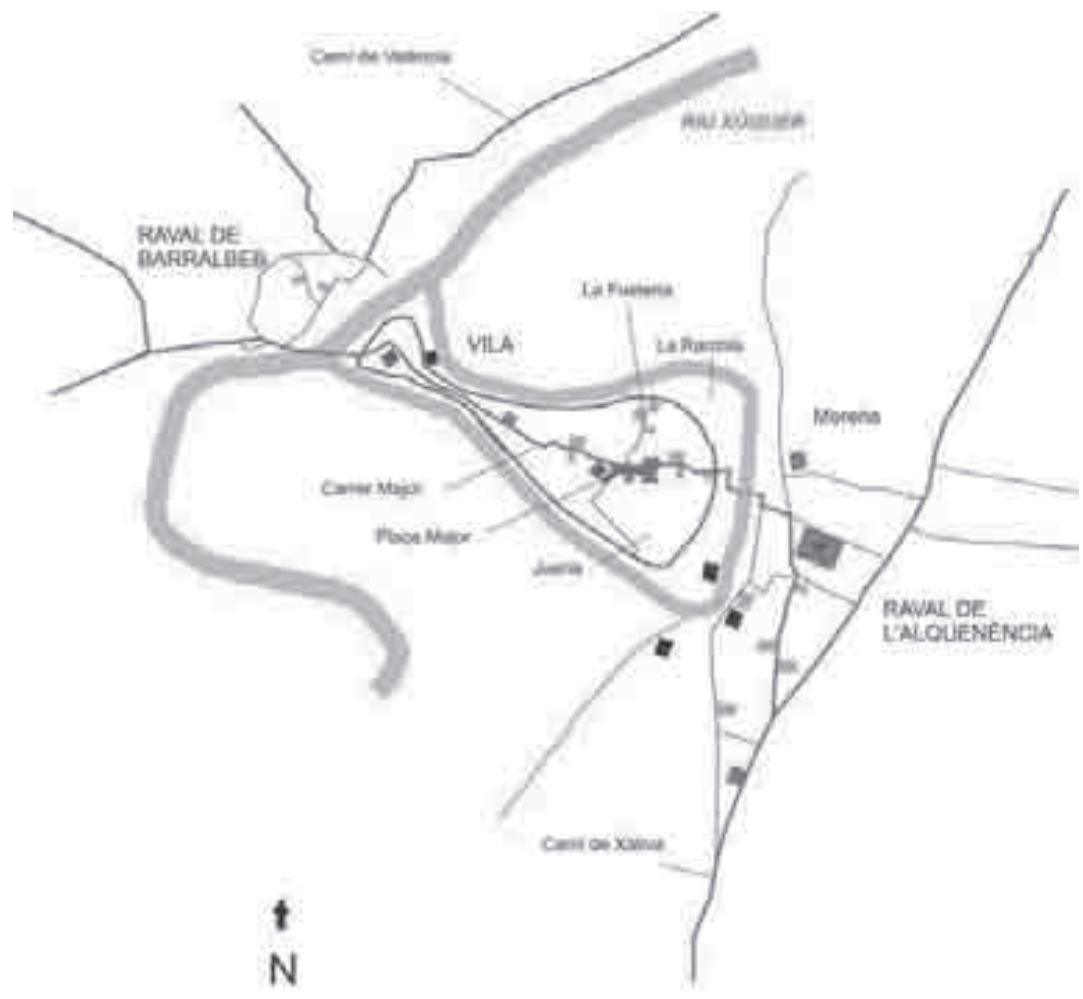

ESCALA 1:200 


\section{ANNEX II}

Percentange d'artesans respecte els veïns tatxats en la peita de 1399-1400 i 1400-1404 en el terme d'Alzira

\begin{tabular}{|l|c|c|c|}
\hline & Veïns & Artesans & \% dels veïns \\
\hline Vila & 606 & 157 & 25,9 \\
\hline $\begin{array}{l}\text { Raval de } \\
\text { l'Alquenència }\end{array}$ & 337 & 47 & 13,9 \\
\hline $\begin{array}{l}\text { Raval de Ba- } \\
\text { rralbeb }\end{array}$ & 160 & 19 & 11,9 \\
\hline Alqueries & 773 & 12 & 1,6 \\
\hline TOTAL & 1.876 & 235 & \\
\hline
\end{tabular}

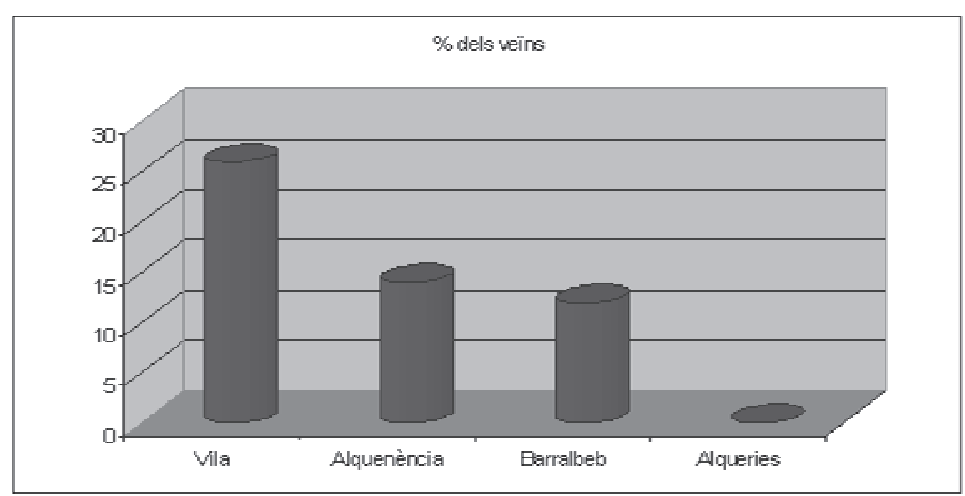




\section{ANNEX III}

Percentatge segons l'activitat principal dels artesans en les distintes zones d'Alzira, atenent el seu lloc de residència, a partir de la peita del 1400-1404

\begin{tabular}{|c|c|c|c|c|}
\hline & VILA & & RAVALS & \\
\hline $\begin{array}{c}\text { Sector pro- } \\
\text { fessional }\end{array}$ & Artesans & Percentatges & Artesans & Percentatges \\
\hline Tèxtil & 69 & $44 \%$ & 16 & $24,2 \%$ \\
\hline Fusta & 31 & $19,8 \%$ & 8 & $12,1 \%$ \\
\hline Cuiro & 28 & $17,8 \%$ & 3 & $4,5 \%$ \\
\hline Metall & 15 & $9,6 \%$ & 22 & $33,3 \%$ \\
\hline Alimentació & 8 & $5,1 \%$ & 12 & $18,2 \%$ \\
\hline Construcció & 6 & $5 \%$ & 5 & $7,5 \%$ \\
\hline TOTAL & 157 & & 66 & \\
\hline
\end{tabular}

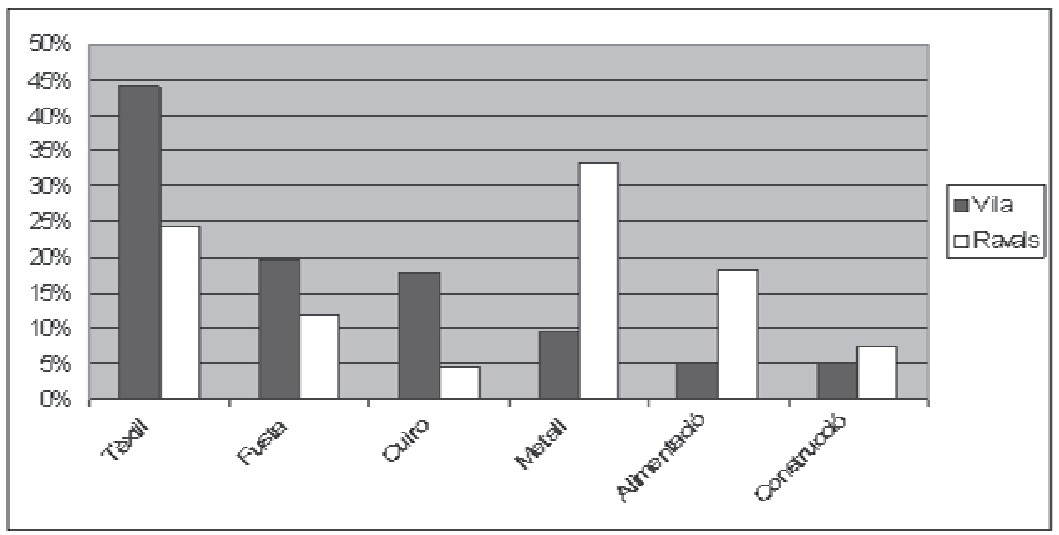


